\title{
Research on efficient implementation of ERP in small and \\ medium-sized breeding enterprises in China
}

\author{
Yong $\mathrm{Li}^{a^{*}}$, Bing $\mathrm{Liu}^{a}$ \\ ${ }^{a}$ Collage of Computer Science and Engineering, CCUT, P.R.China \\ *Corresponding author: Yong Li, Master, liyong@ccut.edu.cn
}

\begin{abstract}
In China, for most small and medium-sized breeding enterprises, the implementation effects of Enterprise Resource Planning (abbreviated as ERP) are unsatisfactory. This paper discusses features of small and medium-sized breeding enterprises first, and then gives the key to implement ERP effectively in the management of small and medium-sized breeding enterprises from six aspects according to many years of the experience of the author in developing and implementing ERP. Hopefully this paper can provide some useful suggestions for small and medium-sized breeding enterprises to implement ERP, so as to enhance the management level and economic benefit of enterprises.
\end{abstract}

Key words: small and medium-sized enterprises; enterprise management; livestock breeding; enterprise resource planning

\section{Introduction}

In order to enhance their own market competitiveness, more and more small and medium-sized breeding enterprises have put the ERP system into the agenda. However, the effect of implementing ERP is not satisfactory. ${ }^{1}$ How to enhance the success rate of ERP implementation is a difficult problem for such kind of enterprises.

Small and medium-sized breeding enterprises in China have some significant features. First of all, their management foundation is weak, especially small and medium-sized private enterprises, some of which still keep very strong traces of family business. ${ }^{2}$ Secondly, most of them are in the downstream of the industrial chain, with less funds and smaller scale, being in a weak position in the market, which are easily affected by market fluctuations. ${ }^{3}$ Thirdly, in order to adapt to changes in external environment, their business forms are flexible and changeable, which brings great challenge to the management. Finally, overall quality of employees is not high, especially the cultural level of employees of grass roots is limited, with strong mobility. These features determine that, in order to implement ERP successfully in small and medium-sized breeding enterprises, the "take-ism" is unable to be carried out mechanically, but diagnosis and treatment according to concrete situation shall be implemented based on complete investigation. 


\section{Suggestions for implementing ERP effectively in the management of small and medium-sized breeding enterprises}

Now, this part gives the key to implement ERP effectively in the management of small and medium-sized breeding enterprises from six aspects according to many years of the experience of the author in developing and implementing ERP. Specifically, the key lies in how to conduct following six aspects.

\subsection{Strengthen the execution capability of the ERP project team}

In the enterprise, there shall be a senior leader with the prestige, understanding business and being familiar with enterprise management to serve as the leadership core of the ERP project team, which is the consensus of everybody. However, only possessing this is still unable to guarantee the implementation of various policies and measures in the project. In small and medium-sized enterprises (abbreviated as SMEs), the execution capability shall be even emphasized. Only the project team with high the execution capability is able to finish the work quality guaranteeing the quality and being as per proper amount. How to enhance the execution capability of the project team? In addition to a leader with both the ability and integrity, there shall also be feasible plans and timely and effective communication. The work progress of SMEs often changes with market change, with poor planning. Therefore, in the process of implementing the ERP, there must be a rolling plan combined the backbone contents with detailed ones. The plan shall be scientific, reasonable and feasible. Sometimes implementing personnel have drawn up the work plan only on the basis of the experience or understanding of partial situation of the enterprise, resulting in that the actual work is unable to be guided by the plan and the plan is delayed and modified at will. This case will not only undermine the seriousness of implementation work, but also make the implementation work be delayed for long-term, causing that the cost of implementation increases constantly, and the execution capability is greatly reduced. Moreover, the project team shall maintain timely and effective communication, so that the unified thought and unify unified understanding can be realized, to promote the timely and effective advancing of the implementation work. It can be said that, in SMEs, the execution capability is the fundament of the success or failure of a project.

\subsection{Grasp the foundation, make clear the idea, and conduct the training first}

Self-owned condition and personnel quality of SMEs are various, which requires that implementation personnel shall not deal with SMEs in accordance with the normal training thought. And they shall focus on basic training and concept training in the content based on the actual situation of SMEs, and for the time, the training in advance or alternated training shall be carried out, so that the atmosphere of learning ERP and applying ERP can be created in the enterprise. Upon the establishment of the project team, according to actual situation of the enterprise, the effect and significance of launching ERP for own enterprise shall be interpreted in simple language combined with the characteristics of enterprise management in the project starting meeting, so that all the staff can support the ERP project heartfeltly, to 
carry out the implementation actively, and clarify the wrong understanding and panic mind of people on ERP. Subject to the investigating and studying on the demand, the training of basic computer knowledge and basic knowledge of ERP can be targeted to grass-roots operation personnel to carry out, and training of ERP concept can be carried out for middle and senior managing personnel, to unify their minds to correct understanding on ERP. The author have encountered a case in practice, some middle-level leaders of an enterprise believe that the purpose of ERP is to reduce their workload, so their requirements on the ERP always focuses on this point how to minimize the workload in the implementation, which has violated the fundament of ERP, bringing obstacles to the implementation work. Subject to in-depth communication, their idea has been finally changed. For the situation similar to this case, if the concept training is carried out for them at the beginning of the implementation work, obstacles of subsequent implementation will be swept off. Finally, before the commissioning on the line, the training of application level shall be carried out for employees.

\subsection{Distinguish the principal contradiction, and tackle key problems}

SMEs have diverse forms of business and non-standardized management, which may show a sense of disorder when conducting demand investigating. At this time, implementation personnel are required to maintain a sober mind, to grasp the principal contradiction of the enterprise, to seek the fundamental reason, solving problems at a touch of the hand.

For example, in one enterprise, sales team is unable to deliver timely, and customer satisfaction is low, with high loosing rate. Production department and sales department are unable to coordinate very well, workshop staff complain that production plan changes too fast and production scheduling is difficult, so production schedule is unable to be controlled. Some materials have a long procurement cycle, but the lead time is too short, the phenomenon to suspend work while waiting for materials is serious. The management of products and semi-finished products in the warehouse is vacant. The quality inspection for incoming materials is vacant, the warehouse is damaged and production scrap is serious. The production cost is difficult to be determined, the management of intercourse funds is difficult, financial data are not enough to support decision-making of high-level and other problem. Getting rid of complicated superficial phenomenon, it is realized that the disconnection of sales and production is an unlocking key to solve the dilemma, as long as conducting information sharing between the sales and production, problems in the warehouse, procurement, after-sale service and other departments will be solved easily. The scientific and effective material management is a key to solve financial chaos, as long as conducting real-time tracking materials in entire link from the purchase to sales, the flow of materials in business will be straightened out, financial cost data will be also accurate and the management of current account funds will be also clear. ${ }^{4}$ In this case, the superficial problem seems complicated, but as long as these two points of information sharing and material flow are controlled, the confusion of enterprise management can be fundamentally turned around. It not only can get quick result, but also can enhance the confidence of enterprises in all levels to do it in this 
way.

2.4 Start from the practice of enterprises, respect for the reality, and standardize carefully business processes.

Business processes of SMEs are generally non-standardized, and some of those are even very confusing. This gives us the feeling that, as long as implementing ERP, the business process must be restructured. ${ }^{5}$ In fact, we have to carry out a concrete analysis on concrete conditions here. It is discovered in the process of the implementation that, the main reason why business processes of some SMEs are confusing is not the management problem, but the problem caused due to adapting to the changing external environment. That is to say, because SMEs are in the downstream of industry chain in the market, capital, technology and other reasons caused by their weak position in the market, only to create a strong group by passive to meet the rules of the game. In this passive responding, SMEs are gradually out of their own management processes and get into confusion in business level.[4] This phenomenon is unique in SMEs, and also the link required being paid attention to in the implementation of ERP. Blindly restructuring such kind of seemingly confused business management shall not be conducted without any analysis, which can only cause a "shock" of the enterprise, ultimately resulting in overall failure of ERP implementation, and even the bankruptcy of the enterprise.

Then how should this kind of case be dealt with? In traditional Chinese medical science, there is a saying "The serious disease shall be treated slowly". It means that, when a person suffers from a serious disease, because the body is weak, he is not allowed to give medicine immediately, but only to promote healthy factors of him first, reinforcing the vital essence and eliminating the pathogenic factor, and then give medicine against the infection, finally curing the disease permanently. It is inspired from this that, when facing this case in the enterprise, the rationality of the existing of such situation shall be respected first, and business process optimization shall not be carried out blindly, but shall strive for solving it in the system by flexible method. If it is unable to be solved flexibly, related personnel shall be negotiated with to adopt the operation method combining the artificial work with the system, or coordinated with small secondary development (Large secondary development is not advocated), and deepened reconstruction will not be carried out until other business management is straightened out and enterprise strength is reinforced. In this way, ERP application in SMEs is achieved surviving first and then planning to develop.

2.5 Match the management demand with business practice, and advocate moderate management, to avoid that the management requirements are disconnected from business reality.

Many managers of SMEs have urgent demand for the application of ERP, which is not only the need of business management, but also the need for enhancing own competence of modern managers. ${ }^{6}$ Therefore, some managers will require their subordinates with higher and stricter criteria, and also expect the ERP system very high accordingly. They always say, 
"XXX Company is doing like this, and we'd better do the same". It shall be affirmed first not an evil deed, but everything too much is as bad as too little, it is meaningless to enhance the management level blindly beyond the actual business level of the enterprise, which not only has violated the original intention of managers, but also will bring great harm to the business operation.

In practical work, such an example has been encountered, the Financial Manager requires that warehousing management shall be conducted for semi-finished products produced by each working procedure, which is conducive to material monitoring of the workshop and conducive to cost accounting, and problems will be discovered timely and solved timely. However, in actual production process, productions of considerable proportion are closely connected, if the warehousing is conducted, the next working procedure is inevitably required to carry out production material requisition before subsequent production, which has not only interrupts the production process, but also increased work intensity of workshop personnel and management cost. Although management requirements of the Financial Manager are good in management thinking, they are finally aborted due to being unrealistic.

\subsection{Implement in one vigorous effort, to avoid the interruption.}

Stop in halfway is a taboo in the implementation of ERP. For SMEs, because of the work planning is not strong and unexpected events are many, this interruption phenomenon in the implementation is much common. For example, the interruption of the implementation is caused due to the relocation of workshop building, enterprise restructuring and other reasons. The interruption is long, causing unnecessary risk to the project. For example, some enterprises have shelved the implementation work for long term, when re-implementing, the former project team has not existed any longer, and all of work shall be restarted from the new, resulting in huge waste of manpower and material resources. After the interruption, due to various reasons, business needs of some enterprises have changed greatly, causing directly that the software purchased previously is not suitable for the changed demand, making the ERP project wither on the vine. This causes huge loss to both parties of the implementation.

Therefore, the interruption shall be avoided as far as possible when implementing the ERP; in case that the implementing were forced to be interrupted, the risk shall be informed, to make clear the responsibility, confirm the time of the suspension and resumption and urge to resume in time.

\section{Conclusions}

SMEs have changeable business forms, the project with long implementation cycle has not been completed yet, but the original demand has changed many times, which brings very great risk to entire ERP project. The staged objective and ultimate objective of the project shall be set at the beginning of the project, recorded them in the form of document. Thus, a staged objective is confirmed whenever completing a staged task, stage, and leaders at all levels can see implementation results of each step objectively, so it is implemented carefully and make steady progress, the ultimate objective of the project will be able to achieved, and 
the entire project can pass the acceptance successfully, being fruitful. Otherwise, in the face of the needs emerging endlessly, the implementation team struggles to cope with, leaders at all levels only see unceasing investment instead of achievement output, and will be downhearted for the ERP project and lost the confidence at the long last, resulting in that project falls short of success for lack of a final effort, such examples are too numerous to enumerate. Therefore, only setting reasonable staged objective and ultimate objective, the ERP project can move forwards according to the established direction, and only by this way, it can be ensured that informationization investment of enterprises can obtain timely return, and enterprises can embark on a development way of informationization construction with virtuous cycle.

Small and medium-sized breeding enterprises in China account for a large proportion in agriculture and animal husbandry, therefore, it has the remarkable social and economic benefits to research management and operation characteristics of such kind of enterprises to allow their management to be raised to a new level with the real assistance of ERP.

\section{Acknowledgements}

This paper is one result of a project supported by the 12th Five-Year Research Plan of Education Department of Jilin, China. (Grant NO. 2015[84] )

\section{References}

1. W. J. Jiang,J.B. He,Z. G. Jin, The History and Prospect of ERP Application of Chinese Manufacturing Enterprises[J]. Applied Mechanics and Materials, 2011,1071(42): 367-370.

2. Y. Zeng, Design and Implementation of ERP System for Small and Medium Sized Enterprises [A]. Information Engineering Research Institute, USA.Proceedings of 2014 5th International Conference on Information Technology for Manufacturing Systems (ITMS 2014) [C].Information Engineering Research Institute, USA, 2014.5:725-729.

3. S. Laukkanen,S. Sarpola,P. Hallikainen, Enterprise size matters: objectives and constraints of ERP adoption[J]. Journal of Enterprise Information Management, 2007,20(3): 319-334.

4. S.I Chang,S.Y. Hung,D. C. Yen,P.J. Lee, Critical Factors of ERP Adoption for Small and Medium-Sized Enterprises: An Empirical Study[J]. Journal of Global Information Management (JGIM), 2010,18(3):82-106.

5. X. Chen, R. Techakittiroj, The Factors Affecting Successful Implementation of ERP in Nanjing Manufacturing SMEs[J]. International Journal of Asian Business and Information Management (IJABIM), 2011,2(3):15-26.

6. W.L. Shiau,P.Y. Hsu,J.Z. Wang, Development of measures to assess the ERP adoption of small and medium enterprises[J]. Journal of Enterprise Information Management, 2009,22(1):99-118. 